\title{
Adsorption efficiency of carbon from treated sugarcane bagasse in removing chromium (VI) from aqueous solutions by optimization of adsorption parameters
}

\author{
Sucharita Tandon* and N. Nandini \\ Department of Environmental Science, Bangalore University, Jnanabharathi Campus, Bangalore-560056, INDIA \\ *Corresponding author. E-mail: sucharita.tandon@gmail.com
}

\begin{abstract}
Adsorption is one of the effective techniques for removal of chromium (VI) from wastewater. In the present study, efforts have been made to develop adsorption technology for removing Chromium ( $\mathrm{Cr}$ ) VI from aqueous solutions by using sugarcane bagasse a waste which is left after taking out the juice. Activated carbon was prepared from waste sugarcane bagasse by chemical activation with orthophosphoric acid and burning for $3 \mathrm{hrs}$. Batch adsorption studies carried out showed that the adsorbent prepared from sugarcane bagasse has a significant capacity in removing $\mathrm{Cr}(\mathrm{VI})$ from aqueous solutions. Optimization of certain adsorption process factors i.e. $\mathrm{pH}$, agitation time; adsorbent dose and adsorbate concentration were also made.
\end{abstract}

\section{Keywords: Adsorption efficiency, Adsorbent, Adsorbate, Chromium (VI) and Sugarcane bagasse} \begin{abstract}
INTRODUCTION
Chromium and its compounds are toxic metals introduced into natural water from a variety of industrial wastewater. The major sources are from Textile Dyeing, Leather Tanning, Electroplating and Metal Finishing industries which cause severe environmental and public health problems. The hexavalent form of chromium is considered to be a group "A" human carcinogen because of its mutagenic and carcinogenic properties. In acute exposure

Materials such as rice husk (Bansal and Sharma,1992), pomogrenate peel (Jambulingam et.al., 2007),Cajanus cajan husk (Ahalya et.al., 2007), wheat bran (Nameni et al., 2008) and tamarind seeds (Babu and Gupta, 2008) have been reported as efficient adsorbents of chromium from aqueous solutions. The aim of present study was to investigate the potential of chemically treated sugarcane bagasse in removing chromium from aqueous solutions.
\end{abstract} it causes death preceded by nausea, vomiting, shock and coma. Ingestion of chromium in the form of potassium dichromate leads to intravascular hemolysis and acute renal failure. Chronic exposure to chromium causes respiratory problems which include ulceration and perforation of nasal septum, irritation of mucous membrane and general branchospasm .It causes "chrome holes", characteristics lesions on skin. The permissible limit of chromium for drinking water is $0.1 \mathrm{mg} / \mathrm{l}$ (as total chromium) in EPA Standard (EPA, 2007). A wide range of physical and chemical processes is available for the removal of $\mathrm{Cr}$ (VI) from wastewater such as electrochemical precipitation, ultra filtration, ion exchange and reverse osmosis. The major drawbacks with these processes are high cost, toxic sludge generation or incomplete metal removal. Adsorption of heavy metals from waste waters is an efficient option. It is a process in which accumulation of solute from liquids occurs on to the surface of a solid. The commercial activated carbon can effectively adsorb chromium from water on its surface but it is also expensive. Agricultural and industrial waste material has been used for preparation of activated carbon by different researchers for the removal of chromium.

\section{MATERIALS AND METHODS}

Adsorbent preparation: The raw material used was sugarcane bagasse, which was bought from the local sugarcane juice shops of Bangalore. It was washed thoroughly under running water to remove any left over sugar and any dirt. It was then dried in sun for 2 days. The material was cut into pieces measuring about 2-3 inches in size. The cut material was later soaked in $25 \%$ orthophosphoric acid for $4 \mathrm{hrs}$. It was then washed with distilled water thoroughly, until $\mathrm{pH}$ was neutral and kept for drying in an electric oven at $120^{\circ} \mathrm{C}$ for $3 \mathrm{hrs}$. These samples were pyrolysed at $300{ }^{\circ} \mathrm{C}$ for $3 \mathrm{hrs}$ in the Table Top Muffle Furnace. The carbon obtained called as phosphoric acid treated Sugarcane Bagasse Activated Carbon (PSBAC) was cooled and powdered using a mortar and pestle. The fibers were sieved on 20 ASTM mesh and were stored for further analysis.

Preparation of stock solution: An aqueous solution of $1000 \mathrm{mg} / \mathrm{l}$ of chromium was prepared by dissolving required amount of potassium dichromate in double distilled water. The samples of required concentration were prepared by diluting the stock solution of chromium. The $\mathrm{pH}$ of the solutions were adjusted by adding an 
appropriate volume of $0.1 \mathrm{~N}$ solution of $\mathrm{HNO}_{3}$ and $0.1 \mathrm{~N}$ $\mathrm{NaOH}$ respectively.

Procedure for metal ion adsorption studies by batch equilibration methods: The known weight of adsorbent material was added to $100 \mathrm{ml}$ of the metal ion solutions with an initial concentration of $0.1 \mathrm{mg} / \mathrm{l}$ to $40 \mathrm{mg} / \mathrm{l}$. The contents were shaken thoroughly using a mechanical shaker rotating with a speed of $100 \mathrm{rpm}$. The solution was then filtered at preset time intervals and the residual metal ion concentration was measured by Atomic Adsorption Spectrophotometer.

\section{Study of effect of variable parameters}

Dosage of adsorbent: The various doses of the adsorbent were respectively mixed with solutions having same $\mathrm{Cr}$ (VI) concentration and the mixture was agitated in a mechanical shaker. The adsorption efficiency for different doses was determined at definite time intervals by keeping all other factors constant.

Initial concentration of metal ion: Adsorption, experiments were conducted with different initial concentrations of chromium (VI) ions ranging from 0.1 $\mathrm{mg} / \mathrm{l}$ to $40 \mathrm{mg} / \mathrm{l}$. All other factors were kept constant.

Contact time: The effect of period of contact on the adsorption of the metal ion on adsorbent in a single cycle was determined by keeping initial metal concentration, adsorbent dosage, $\mathrm{pH}$ of the solution constant.

pH: Adsorption experiments were carried out at $\mathrm{pH}$ 2,4,6 and 8 . The acidic and alkaline $\mathrm{pH}$ of the media was maintained by adding the required amounts of $0.1 \mathrm{~N}$ solution of $\mathrm{HNO}_{3}$ and $0.1 \mathrm{~N} \mathrm{NaOH}$ solution. The parameters like metal ion concentration, dosage of the adsorbent and contact time were kept constant while carrying out the experiments.

Calculations: The adsorption efficiency of sugarcane bagasse $(\%)$ were calculated according to the expressions Adsorption efficiency $\%=(\mathrm{Co}-\mathrm{C}) / \mathrm{Co} \times 100$

Where Co is the initial concentration of metal $(\mathrm{mg} / \mathrm{l})$ and $\mathrm{C}$ is the metal concentration in the solution at the end of the adsorption process $(\mathrm{mg} / \mathrm{l})$.

\section{RESULTS AND DISCUSSION}

Adsorption is the accumulation of solutes dissolved in liquids on to the surface of solids. The adsorbing solid is called adsorbent and the substance to be adsorbed from the liquid is referred to as an adsorbate. Adsorption efficiency is affected by the physical and chemical characteristics of both adsorbate and adsorbent. The methods for preparing activated carbons are often classified as chemical and physical activation methods. Chemical activation method consists of carbonizing a raw material after adding substances that restrict tar formation. In this work chemical activation was done using $25 \% \mathrm{H}_{3} \mathrm{PO}_{4}$. Activated carbons made by chemical activation have a porous and very open structure, ideal for adsorption. The advantages of activation with phosphoric acid include a high yield and lower working temperature. Well developed porosity together with high cation exchange capacity makes phosphoric acid activated carbons from lignocellulosic precursors (sugarcane bagasse) promising material for applications involving metal ion adsorption (Puziy et al., 2005).In the current experiment the extent of adsorption was studied by optimizing various adsorption parameters: $\mathrm{pH}$, adsorbent dose, agitation time and adsorbate concentration.

Effect of pH: pH influences the surface charge of the adsorbent, the degree of ionization and the species of adsorbate. So $\mathrm{pH}$ is an important factor controlling the process of biosorption (Prasad and Rao, 2009). In the present study the effect of $\mathrm{pH}$ was studied over the range 2-8 for chromium initial concentration of $10 \mathrm{mg} / \mathrm{l}$ and $0.1 \mathrm{gm}$ of adsorbent dosage. It was observed that at acidic $\mathrm{pH}$ i.e. $\mathrm{pH}<5$ the adsorption capacity was more. At $\mathrm{pH}$ greater than five a decrease in adsorption efficiency was observed. Similar results were reported by Babu and Gupta (2008) while working on adsorption of chromium on tamarind seeds. The adsorption of metal ions depends on solution $\mathrm{pH}$, which influences electrostatic binding of ions to corresponding metal groups (Ahalya et al., 2007).

Effect of contact time: Contact time has influence on metal uptake and percentage removal of chromium (VI). The effect of contact time on adsorption efficiency of chromium on PSBAC was studied over an agitation time of 30 minutes, 45 minutes, 1 hour and 2 hour. $0.1 \mathrm{gm}$ of PSBAC was shaken at $100 \mathrm{rpm}$ with $100 \mathrm{ml}$ of $10 \mathrm{mg} / \mathrm{l}$ chromium solution. The findings show that the percentage adsorption increased from $30 \%-50 \%$ in first 45 minutes after which it became a constant for next 15 minutes and after that a decrease in the efficiency was observed (Fig 1). Thus the optimum equilibrium time was found to be 45 minutes. This may be due to the complete clogging of available adsorption sites on adsorbent material with the metal ions and unavailability of the free sites. Perhaps the adsorbate forms a thin one molecule thick layer over the surface. When this monomolecular layer covers the surface, the biosorbent capacity is exhausted (Prasad and Rao, 2009).

Effect of adsorbent dosage : The effect of adsorbent dosage on percentage adsorption of chromium is shown in Fig. 2. The adsorbent doses of 0.1 to $1.0 \mathrm{gm}$ of PSBAC were agitated with $100 \mathrm{ml}$ of $10 \mathrm{mg} / \mathrm{l}$ of chromium solution for 45 minutes. It is evident from the results that the adsorption efficiency of PSBAC in adsorbing chromium (VI) from aqueous solutions increases with increase in adsorbent dosage. The percentage adsorption increased up to $100 \%$ from $50 \%$ with increase in adsorbent dosage from $0.1 \mathrm{gm}$ to $0.5 \mathrm{gm}$ and remained constant afterwards 


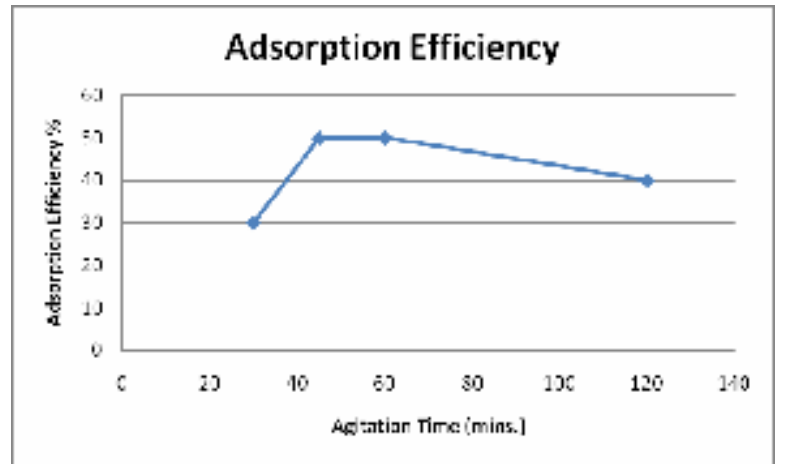

Fig. 1. Effect of contact time on adsorption efficiency of PSBAC.

at $1 \mathrm{gm}$. Studies carried out reveals that ratio between adsorbent dose and adsorbate concentration should be maintained for maximum percentage adsorption.

Effect of initial adsorbate concentration: Adsorption efficiency versus initial concentration is shown in Fig. 3. Different chromium solutions with concentration ranging from $0.1 \mathrm{mg} / 1$ to $40 \mathrm{mg} / \mathrm{l}$ were agitated at $100 \mathrm{rpm}$ for 45 minutes with adsorbent dose of $0.1 \mathrm{gm}$, The percentage adsorption of Chromium (VI) decreases from $100 \%$ to $50 \%$ as the initial concentration of chromium in aqueous solution increased from $0.1 \mathrm{mg} / 1$ to $40 \mathrm{mg} / \mathrm{l}$. Such behavior can be attributed to the increase in the amount of adsorbate to the unchanging number of available active sites on the biosorbent since the amount of biosorbent is kept constant (Prasad and Rao, 2009). Thus Chromium ions are left unadsorbed in solution due to the saturation of binding sites on the available adsorbent. It was also observed that solutions with higher adsorbate concentration should be agitated with same dosage of adsorbent for a longer duration almost 10 hours to get $95 \%$ results. Agitating for 1 hour can also give better results for low adsorbate concentration of $5 \mathrm{mg} / \mathrm{l}$ for same $0.1 \mathrm{gm}$ of adsorbent dosage else the dosage should be increased.100\% removal of chromium was observed in $10 \mathrm{mg} / \mathrm{l}$ chromium solution by agitating the solution with $0.4 \mathrm{gm}$ of PSBAC for 1 hour whereas only $50 \%$ removal was observed by agitating the same $10 \mathrm{mg} / \mathrm{l}$ solution with $0.1 \mathrm{gm}$ of PSBAC for 1 hour.

\section{Conclusion}

The present study concluded that lower dosage of adsorbent prepared from waste sugarcane bagasse was efficient in $100 \%$ removal of chromium (VI) from aqueous solutions having $0.5 \mathrm{mg} / 1$ to $5 \mathrm{mg} / \mathrm{l} \mathrm{Cr}$ (VI) concentration. For treatment of solutions with higher concentration of initial $\mathrm{Cr}(\mathrm{VI})$ higher dosage of adsorbent should be used. The equilibrium time for the adsorption of maximum chromium (VI) from solution having $10 \mathrm{mg} / \mathrm{l}$ of the same on $0.1 \mathrm{gm}$ of adsorbate prepared from orthophosphoric acid treated sugarcane bagasse in the present study was

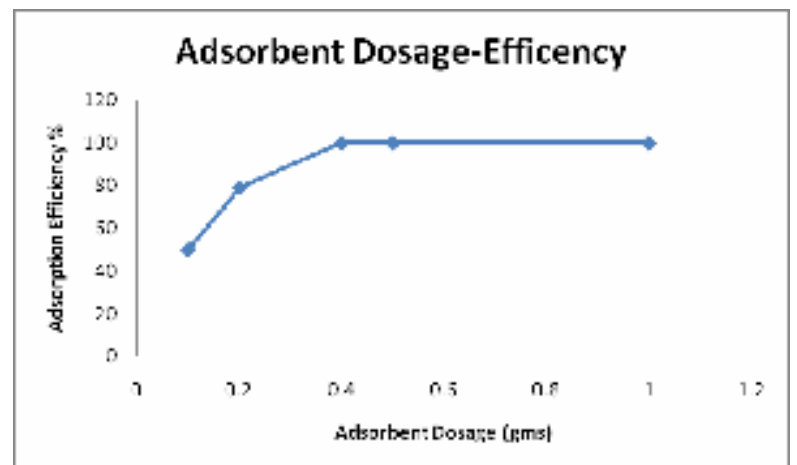

Fig. 2. Effect of adsorbent dosage on adsorption efficiency of PSBAC.

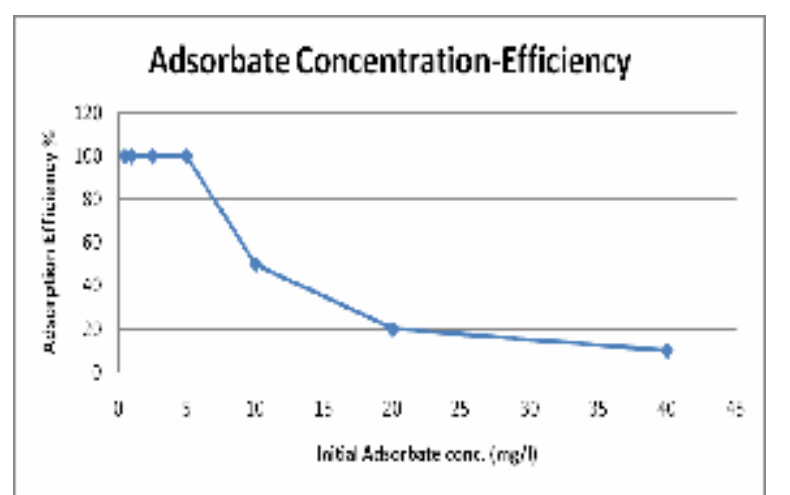

Fig. 3. Effect of initial adsorbate concentration on adsorption efficiency of PSBAC.

found to be 45 minutes. The removal of chromium (VI) increases with increase of adsorbent dosage with maximum adsorption of chromium (VI) at pH less than 5.

\section{REFERENCES}

Akporhonor, E.E. and Egwaikhide, P.A. (2007). Removal of selected metal ions from aqueous solutions by adsorption onto chemically modified maize cobs. International Journal of Applied Environmental Sciences, 2 (2): 93-98.

Adeyiga, A. A., Hu, L. and Greer, T. (2004). Removal of metal ions from waste water with natural waste. Water Science and Technology, 29:3-15.

Ahalya, N., Kanamadi, D.R. and Ramachandra, V.T.(2007). Cr (VI) and Fe (III) removal using Cajanus cajan husk. Journal of Environmental Biology, 28 (4):765-769.

Bansal, T. K. and Sharma, R. H.(1992).Chromium removal by adsorption on rice husk ash. Indian Journal of Environmental Protection, 12 (3):198-201.

Bhatti Inamullah ,Qureshi Khadija , Kazi, R. A. andAnsari Khalique Abdul (2008).Preparation and characterisation of chemically activated almond shells by optimization of adsorption of chromium VI from aqueous solutions. International Journal of Chemical and Biomolecular Engineering ,1(3):150-155.

Babu, B. V. and Gupta, Suresh (2008). Removal of Cr (VI) from wastewater using activated tamarind seeds as an adsorbent. Journal of Environmental Engineering and Science, 7 (5) :553-557. 
EPA(2007).Drinking water standard,Environment Protection Agency., Retrived from : http://www.epa.gov/safewater/ contaminants/index.html

Garacia Macias, A., Diez Diaz, A. M., Serrano Gomez, V. and Gonzalez Fernandez, M.C.(2003). Preparation and characterization of activated carbons made up from different woods by chemical activation with $\mathrm{H}_{3} \mathrm{PO}_{4}$. Smart materials and structure, 12:N24-N28.

Igwe, J. C. and Abia, A. A. (2006). A bioseparation process for removing heavy metals from waste water using biosorbents. African Journal of Biotechnology, 5 (12): 1167-1179.

Jeyanthi, G.. P. and Shanthi, G. (2007). Removal of lead from lead electroplating industrial effluent using sago waste. Journal of Environmental Science and Engineering, 49(1):13-16.

Jambulingam, M., Renugadevi, N.,Karthikeyan, S.and Kiruthika, J. (2007). Adsorption of Cr (VI) from aqueous solution using a low cost activated carbon prepared from pomegranate peel. Nature Environment and Pollution Technology, 6 (1):15-22.

Nameni, A., Moghadam Alavi, R.M. and Arami, M. (2008). Adsorption of hexavalent chromium from aqueous solutions by wheat bran. International Journal of Environmental Science Technology, 5 (2):161-168.

Puziy, Alexander M., Poddubnaya Olga I., Alonso Amelia Martinez, Garcia,Fabian Suarez and Tascon Juan, M.D. (2005). Surface Chemistry of phosphorous-containing carbons of lignocellulosic origin.Carbon, 43:2857-2868.
Prasad, A. and Rao, S. Sarveswara (2009). Removal of copper using microsize coconut husk powder:equilibrium and kinetic studies. Nature Environment and Pollution Technology,8(2): 389-394.

Popuri Rao Srinivasa,Jammala Ajithapriya,Reddy Kachireddy Venkata Naga Suresh and Abburi Krishnaiah (2007).Biosorption of hexavalent chromium using tamarind (Tamarindus indica) fruit shell-a comparative study.Electronic Journal of Biotechnology,10(3):358-367.

Roger, M. Rowell(2006).Removal of metal ions from contaminated water using agricultural residues. In : Proceedings of ECOWOOD 2006 -2nd International Conference on Environmentally-Compatible Forest Products Fernando Passoa University, Oporto, Portugal;pp 20-22.

Rao, M.,Parwate, A.V.and Deshpande, V.P.(2003). Removal of heavy metals by adsorption process using bagasse. Indian Journal of Environmental Protection,23(4):428-433.

Rao , M. and Bhole, A.G .(2000).Removal of chromium using low-cost adsorbents. Journal of Indian Association For Environmental Management., 27(3):291-296.

Siddiqi, M.Z. and Paroor, V.S (1994). Removal of Chromium (VI) by different adsorbents-A comparative study. Indian Journal of Environmental Protection, 14 (4):273-278. 